\title{
On the Flame-Flow interaction under Distributed Combustion Conditions
}

\author{
Ahmed E.E. Khalil and Ashwani K. Gupta* \\ Department of Mechanical Engineering, \\ University of Maryland, College Park, MD 20742, USA
}

\begin{abstract}
Colorless Distributed Combustion (CDC) has shown simultaneous benefits of high combustion efficiency, ultra-low pollutants emission, low combustion noise, uniform thermal field, and enhanced stability. Distributed combustion is fostered by reduced oxygen concentration and high temperature oxidizer to result in distributed reaction over a larger volume of the combustor and uniform thermal field. In this paper, the interaction between the velocity field (characterized through Particle Image Velocimetry) and the reaction region (identified through hydroxyl Planar Laser Induced Fluorescence) is investigated with focus on swirl assisted distributed combustion. A mixture of nitrogen and carbon dioxide was mixed with normal air upstream of the burner to simulate the hot reactive gases. The flowfield was characterized under non-reacting conditions to outline the impact of the added dilution on the flowfield. The results showed dilution to enhance both the inner recirculation and outer recirculation zones. Reacting flowfield, characterized to determine the impact of the temperature rise and density changes, showed maximum

20 velocity region to shift downstream. Comparing the PIV data for reacting conditions with OH-PLIF revealed significant difference between normal swirl and CDC flames. In swirl flame, the flame was located around the shear layer of the entry jet (with both the inner and outer recirculation zones) where the velocity fluctuations and OH-PLIF fluctuations coincided. Flame transitioning to $\mathrm{CDC}$ pushed the reaction zone further downstream to

25 locate at a position of lower velocity than what was found for swirl flames. In addition, the reaction zone occupied a much larger volume with lower signal intensity to exhibit distributed reaction. Experiments performed at same flow rates and velocities but with no reduction in oxygen concentration confirmed that the change in reaction behavior is attributed to the lower oxygen concentration rather than the increased flowrates due to
\end{abstract} 30 dilution.

Keywords: Colorless distributed combustion (CDC), Swirl flames, Particle Image Velocimetry (PIV), OH-Planar Laser Induced Fluorescence (PLIF), Gas turbine combustion.

\footnotetext{
* Corresponding author: Tel.: +1 301405 5276; Fax: +1 3013149477.

E-mail address: akgupta@umd.edu (A. K. Gupta).
} 


\section{Introduction}

Colorless distributed combustion (CDC) offers most promise for near zero emission to conform to increasingly stringent pollutants emission regulation. The performance of CDC has been investigated over a wide variety of geometries, heat release intensities, and fuels [1-5].

5 CDC shares some of the basic principles of high temperature air combustion (HiTAC) that has demonstrated ultra-low emissions, uniform thermal field, and significant energy gains for atmospheric pressure furnace applications [6]. In HiTAC, low oxygen concentration air, preheated to high temperatures, is used for combustion. The temperature of combustion gases in the furnace is some $50-100^{\circ} \mathrm{C}$ higher than that of the preheated low oxygen concentration fuel-air

10 mixture just prior to ignition. The low oxygen concentration in the incoming reactants (only about 2 to $5 \%$ by volume) can be achieved, among other methods, through the internal (or external) recirculation of combustion gases, which also increases the air temperature [6]. In $\mathrm{CDC}$, decrease in oxygen concentration and increase in temperature of the fresh mixture stream is achieved through internal entrainment of hot reactive species from within the combustor. This

15 entrainment and the subsequent adequate mixing prior to ignition are critical components to achieve distributed combustion. Distributed combustion is characterized by volume-distributed reaction over the entire volume of the combustor as opposed to thin concentrated flame front characterized by high reaction rates and presence of local hot spots in normal combustion, to result in the same fuel consumption with lower temperature rise in the combustor. This low

20 reaction rate is achieved through lowering the oxygen concentration of the reactants, and increasing temperature of the reactants (both of which can be achieved through entrainment of hot reactive gases). The distributed combustion regime avoids not only the formation of thin reaction zone but also the hot spot zones in the flame. This helps to mitigate thermal $\mathrm{NO}_{\mathrm{x}}$ 
formation and emission from the Zeldovich thermal mechanism [7]. The overall temperature of the flame is low so that there is no need to dilute the hot gases before introducing them to the turbine. This reduces power requirements of the gas turbine's compressor to directly enhance the gas turbine efficiency and simultaneously enhance both combustor and turbine lifetime.

5 Other technologies have also emerged with focus on addressing pollutants emissions with relevance to gas turbines combustion. These technologies include flameless oxidation (FLOX) [8-9] and moderate or intense low-oxygen dilution (MILD) [10]. However, these technologies have similar goals, the approach and performance is different from CDC.

For all the aforementioned investigations involving CDC, the entrainment of hot reactive 10 gases from within the combustor have resulted in lower emissions and enhanced thermal field uniformity in the combustion chamber. This has been shown through changing the geometry/injection velocity and measuring the entrainment (through PIV) and coupling that with the resultant pollutants emission $[4,11]$. Though these investigations have offered much insight on the role of entrainment, critical questions remain concerning the amounts of entrainment 15 required to achieve distributed combustion.

The critical entrainment amount was investigated in a swirl burner with focus on determining the amounts of oxygen concentration at which volume distributed reaction occurs [12]. The swirl burner allowed for good optical access for laser diagnostics. This work [12] showed that distributed reaction occurs at an oxygen concentration of about $15 \%$ with the reactants

20 introduced at room temperature. This investigation revealed that the reduction in emission is from oxygen concentration reduction rather than dilution of the gases. This was confirmed by performing experiments with no dilution, increased air and fuel flow rates, air dilution (lower equivalence ratio) and $\mathrm{N}_{2}-\mathrm{CO}_{2}$ dilution (lower oxygen concentration) conditions [13]. Reynold's 
number was kept constant for the latter three investigations to eliminate velocity change effects. Lowering oxygen concentration demonstrated lower emission as compared to adding more air or increasing air and fuel amounts to increase overall velocity. In addition, distributed combustion was only evident in lower oxygen concentration cases while the other cases demonstrated the

5 traditional swirl flame structure as evidenced from the $\mathrm{OH}^{*}$ chemiluminescence images shown in Fig 1. Thermal field investigation also showed that the thermal field under distributed combustion is substantially different from that of a swirl flame. The temperature variation was negligible with a uniform temperature distribution [13].

In this paper, the velocity flowfield under swirl flames and distributed combustion conditions 10 is investigated with focus to extract the main flow features. The flowfield measurements are coupled with hydroxyl $(\mathrm{OH})$ planar laser induced fluorescence to determine the interaction between the flowfield and the reaction zone. OH-PLIF is picked over $\mathrm{OH}^{*}$ chemiluminescence as it offers both average and instantaneous measurements over a thin plain (laser sheet thickness). On the other hand, $\mathrm{OH}^{*}$ chemiluminescence is a line of sight method. Though Abel

15 transform (Abel inversion) has been successfully applied to axisymmetric flames, as the flame transformed to distributed combustion, the inversion results were unsatisfactory. Several researchers have combined velocity field and OH-PLIF (mean and instantaneous) data to study the behavior of swirl flames and jet flames in details [14-19], resulting in useful insights. Comparing the velocity field and OH-PLIF field under swirl flames and distributed combustion

20 conditions provides the main differences between them to help explain the flame characteristics under each case. The details of the experimental facility and the laser diagnostics are given next. 


\section{Experimental Facility}

The experiments were performed using a swirl burner with a $45^{\circ}$ swirl angle. Details of the swirl burner can be found elsewhere [20]. A mixture of $90 \%$ nitrogen $10 \%$ carbon dioxide was used to simulate entrained product gases. Laminar flow controllers with an accuracy of $\pm 0.8 \%$ of reading and $\pm 0.2 \%$ of

5 full scale were used to control the air and nitrogen flow rates, leading to an overall accuracy of about $1.5 \%$ of the reading. Methane and carbon dioxide flow rates were controlled through gravimetric flow controllers with an accuracy of $1.5 \%$ of full scale. Fuel (methane) was injected at the center of the swirler in a non-premixed configuration. Figure 2 shows the flow configuration of the swirl while Fig. 3 shows a schematic diagram of the facility and the diagnostic tools.

10

\subsection{Particle Image Velocimetry}

For measuring velocities, a particle image velocimetry (PIV) system was used. The camera was located at a distance of $0.5 \mathrm{~m}$ away from the laser plane. The camera view covered an area of $8.4 \mathrm{~cm} \times 6.3 \mathrm{~cm}$. Portion of the air supplied to the combustor was diverted to a fluidized bed

15 seeder, where the seeding particles were picked up by the air and then combined with the main line as shown in Fig. 3. The portion of air diverted was about $10 \%$ and the flow rates of the main air and seeding air were controlled to reach the desired total air flow for all the experimental conditions examined. The seeding particles used were Alumina with a nominal particle diameter of $2 \mu \mathrm{m}$. The laser sheet beam had a thickness of about $1 \mathrm{~mm}$. Table 1 summarizes the different

20 parameters of the PIV system. For data processing, PIVLab was used [21]. For each data set, four passes were performed with interrogation window size of $64,32,16$, and 8 pixels with $50 \%$ overlap. The interrogation window size was selected such that the maximum displacement was less than third of the window size. High reflection regions and noise were handled through masks to eliminate erroneous vectors resulting from the high signals, leading to areas of "no vectors" in 
the velocity field. The PIVLab output was further processed in Matlab to obtain mean and fluctuating velocities and other relevant quantities. The estimated error in the PIV experiments based on particles used (material and size) as well as velocity gradients were less than 15\% [22]

\subsection{Planar Laser Induced Fluorescence}

The excitation of $\mathrm{OH}$ radicals requires activation through a specific laser wavelength. This is achieved through a dye laser system with a UVT (Ultraviolet Tracking) unit with active wavelength control to eliminate laser line "walking" (drop in power). The dye laser system consists of a pump laser (Continuum PL9000) used to excite "pump" the dye, a dye laser unit

10 (ND6000), where Rhodamine 590 dye is circulated and exposed to the pump laser. The dye laser output had a wavelength of $\sim 563 \mathrm{~nm}$ which is introduced to the UVT unit to be frequency doubled to result in the required wavelength for a target excitation line $\left(\mathrm{Q}_{1}(6)\right)$. The resultant laser beam was then turned into a laser sheet with a sheet thickness of about $\sim 1 \mathrm{~mm}$ to cover the same area of interest as that used for the PIV laser system. To capture the OH-PLIF signal, an

15 Intensified Charge Coupled Device (ICCD) camera was used. A high voltage pulse generator was used to time the laser and the ICCD camera as well as power the intensifier for the short exposure time needed (60 ns).

The $\mathrm{OH}$ intensity was obtained from the $\mathrm{Q}_{1}(6)$ activation line as it demonstrated highest $\mathrm{OH}$ signal. The wavelength was chosen based on the work of Dieke et al. using LIFBASE software

$20[23,24]$. This line is activated with a laser power of about 19mj. For each experiment, 100 images were acquired and averaged. Noise signal was recorded just outside the activation range (+/- 0.05 Angstrom) to maintain the laser power at the same level as the activation line. One 
hundred images of the background noise were obtained and averaged which were then subtracted from the averaged data to remove the background noise.

\section{Experimental Conditions}

5 The experimental investigations reported here were focused on obtaining the velocity field and $\mathrm{OH}$ distribution for all the cases examined. As these fields were obtained, comparisons between them helped to establish interaction between the velocity field and the reaction zone under different conditions. For this purpose, three conditions were chosen. The first one is a confined swirling flame configuration, which represents a baseline case. The second represents

10 distributed combustion while the third is a confined swirler case operating at lower equivalence ratio, representing air dilution. Figure 4 shows the flame behavior upon dilution with $\mathrm{N}_{2} / \mathrm{CO}_{2}$ mixture.

Table 2 summarizes the operating conditions for each of the experimental cases along with the errors of every flowrate. It is noteworthy that the three conditions presented here were down-

15 selected for laser diagnostics from a wider range of experiments representing different amount of dilutions and oxygen concentration in the mixture. The oxygen concentration is defined here as the amount of oxygen in the fresh non-fuel reactant divided by the total amount of the non-fuel reactant (air and nitrogen-carbon dioxide mixture). For distributed combustion, an oxygen concentration of $14.5 \%$ was selected for this experiment as further reduction in oxygen 20 concentration resulted in some instability during PIV experiments. The examined conditions were chosen to have the same thermal load (input fuel flowrate) that provided the differences in flame behavior at the same input energy. The focus is to compare the flowfield under normal swirl (cases 1 and 4) and distributed combustion (case 2 and 5). Case 2 uses $\mathrm{N}_{2} / \mathrm{CO}_{2}$ mixture to 
simulate the impact of internal recirculation of reactive species. The role of temperature of these diluents has been examined previously, where the distributed combustion was achieved regardless of the gas temperature [25]. Cases 3 and 6 represents a normal swirl flame under same flow velocities and heat input as that of cases 2 and 5, but at an oxygen concentration of

$521 \%$ rather than the reduced oxygen concentration achieved through adding $\mathrm{N}_{2} / \mathrm{CO}_{2}$ mixture.

\section{Results and Discussion}

\subsection{Non-reacting flow field}

Initial experiments focused on obtaining the flowfield under isothermal conditions. Such

10 flowfield helps to provide a base line case for the combustor flowfield behavior under confined and confined diluted conditions (cases 1-3). Figure 5 shows the flowfield for the confined swirl flow (case 1) with the velocity vectors and axial velocity contours (left) as well as the root mean square of the velocity fluctuations (right). This flowfield demonstrates a base case of swirl flow with center recirculation zone as seen from the presence of negative axial velocity at the center

15 of the burner (magnitude about $-1.5 \mathrm{~m} / \mathrm{s}$ ).

As the diluents were introduced to the confined burner, through either $\mathrm{N}_{2} / \mathrm{CO}_{2}$ addition or excess air addition, the velocity field behavior changed. First, the mean axial velocity values increased through the view field as result of the added flowrates, see Fig. 6. The flow rates were increased by about $45 \%$ (due to the added diluents) which resulted in a $\sim 20 \%$ increase in the

20 axial velocity. In addition, the radial velocity increased with the jet moving outwards faster than the previous cases. In addition, the outer recirculation zone near the walls at the bottom of the combustor was more evident as the flow rates increased. On the other hand, the velocity fluctuations were significantly higher throughout the region of interest with a high value found at 
the centerline near to top of the center recirculation zone. This feature was not detected in the previous case. It is noteworthy that cases $2 \& 3$ demonstrated the same isothermal flowfield as their Reynolds' number varied by $0.5 \%$, consequently only case 2 is presented.

These experiments outline the impact of dilution on the mean and fluctuating velocity

5 distribution. Increase in flowrates (due to either $\mathrm{N}_{2} / \mathrm{CO}_{2}$ addition or excess air addition) resulted in higher velocity and turbulence across the combustor and a stronger recirculation zone at the center and at the sides. Establishing these distinctly different flowfield and turbulence behavior is critical to isolate the fluid dynamics effects from those of combustion and temperature variation for the reacting experiment cases. These effects are discussed next.

10

\subsection{Reacting flow field}

The reacting flowfield under confined and confined diluted conditions for the swirl burner was examined for cases 4-6. First, the swirl burner flowfield was examined under reacting condition with no dilution (case 4). The resultant flowfield is shown in Fig. 7 with the contours

15 of mean axial velocity vectors (left) and the root mean square of velocity fluctuations (right).

The maximum axial velocity was found to be shifted slightly downstream as compared to the non-reacting case, corresponding with the combustion region, where the temperature increase results in a density decrease and an increase in velocity for the same mass flow rate (see Figs. 5 and 7). On the other hand, the velocity fluctuations were mainly around the reacting region and

20 decreased in value with progression in axial distance downstream. A central recirculation zone was also evident at the center. For the reacting case, strong laser reflections from the quartz led to high noise signal at portions of the flowfield, which were masked as seen in Fig. 7. 
Dilution of the mixture changed the flowfield significantly. Figure 8 shows the velocity profile and velocity fluctuations under the reacting confined $\mathrm{N}_{2} / \mathrm{CO}_{2}$ diluted condition (case 5). It is to be noted that this flowfield represents distributed combustion as the oxygen concentration in the reactants fell below $15 \%[12,13]$. The first thing to notice is that the central recirculation

5 zone was strengthened further (as seen from the increased negative axial velocity, compared to that shown in Fig. 7). In addition, the outer recirculation zone, shown previously in Fig 6, was also present. The velocity fluctuations were higher under this condition as compared to all the other cases reported here. Similar to the reacting confined case, the zero velocity areas correspond to high reflection noise that was masked.

10 Comparing the flowfield of Figs. 5-8, one can see that the velocity values were mainly dictated by the increase in flowrates (no dilutions vs. dilution) and increase in temperature (reacting cases provided high velocities due to the reduced density). As the velocity field was established, OH-PLIF was performed next to compare the velocity fields with reaction zones.

\subsection{Reaction zone and velocity field}

The OH-PLIF was performed to outline the reaction distribution behavior under different conditions and corroborate the $\mathrm{OH}$ field with the velocity field. This comparison outlines the differences in flame behavior under normal swirling flames and distributed combustion. The mean OH-PLIF signal of the confined swirling flame was compared with the corresponding flow

20 field. Figure 9 shows the mean OH-PLIF signal along with the velocity vectors for this case.

A comparison of the results shown in Fig. 9 for $\mathrm{OH}$ and flowfield reveals that the maximum $\mathrm{OH}$ signal is radially outwards of the high velocity region. In addition, the $\mathrm{OH}$ region extended all the way radially until the wall (at $\mathrm{x}=0.04$ ), while the high velocity jet was almost vertical at 
$\mathrm{x}=0.024$. It is noteworthy that there was no $\mathrm{OH}$ signal detected at the central recirculation zone. This behavior, where the mean OH-PLIF signal is radially outwards of the entry jet (high velocity area) is typical of swirling flames and have been documented in the literature. Comparing the velocity field and mean OH-PLIF signal of Weigand et al. [14], one can outline

5 this behavior where the OH-PLIF signal is radially outwards of the high velocity region, especially for the lower velocity cases.

One can also compare the standard deviation of the $\mathrm{OH}$ signal and the velocity fluctuation, as shown in Fig. 10. The standard deviation of the $\mathrm{OH}$ signal and the fluctuating velocity agree favorably well (in terms of the $\mathrm{OH}$ fluctuation maximum value that correspond to the outside

10 shear layer of the entry jet). This shows a close coupling between the velocity and mean $\mathrm{OH}$ signal (Fig. 9) as well as the standard deviation of the $\mathrm{OH}$ signal and the velocity fluctuations (Fig. 10).

The reaction takes place at the shear layer between the main flow and the recirculation zone (where the velocity fluctuations were at its highest). This has also been previously shown in the

15 literature [14-17]. This was not only true for swirling flames but also for jet flames [18, 19]. This behavior explains why the reaction zone seen through mean OH -PLIF was radially outwards of the high velocity region. These observations [14-19] were based on average and instantaneous images of PLIF and PIV; however, instantaneous data comparison was not possible during the experiments presented here.

20 As one transitions to distributed combustion mode, through reducing oxygen concentration in the reactants, the flame and velocity flowfield looked completely different. Figure 11 shows the mean OH-PLIF signal as well as the mean axial velocity for distributed combustion case 5. 
Contrary to the previous case, the mean OH-PLIF was found to be further downstream of the inlet, where the velocity was much lower. This is in contrast with the established behavior of swirl flames as discussed earlier. Also, the reaction zone extended near the wall and towards the center of the combustor around the inlet swirling jet. In other words, the $\mathrm{OH}$ mean signal seems

5 to cover most of the viewing area with the exception of the high velocity area. Somewhat similar behavior was reported in the literature, where the flame extends to have an ' $M$ shape' rather than the traditional 'V shape' associated with swirl flames, however, these features were different from what is demonstrated here. Arndt et al. examined a swirl combustor where, under certain conditions, the flame transitions between V-shape and M-shape unpredictably [26]. However, the

10 flame shape demonstrated under distributed combustion is extremely stable and does not move back to traditional swirl flame unless the oxygen concentration was significantly increased (amount of $\mathrm{N}_{2} / \mathrm{CO}_{2}$ mixture significantly decreased). Oberleithner et al. also demonstrated an Mshaped flame under low equivalence ratio and increased heat loads [27]. However, Fig. 1 showed that decreasing the equivalence ratio or increasing the heat load did not result in a flame shape 15 change, confirming that the flame shown here is distinctively different.

The difference in flame behavior is related to the decrease in oxygen concentration in the reactants. Decrease in oxygen concentration due to dilution decreases the laminar flame velocity [28-30]. Consequently, the reaction zone was established further downstream at lower flow velocity regions. In addition, the lower oxygen concentration resulted in a lower reaction rate 20 [31] and the reaction zone occupied a larger volume to consume the same amount of fuel.

In addition, the OH-PLIF maximum signal was found to be lower $(\sim 25 \%)$ than that of the undiluted case to indicate a more distributed reaction (800 a.u. vs. 1000 a.u. for the same PLIF 
system parameters, see Figs. 9 and 11). This reduction can be related to the flame being spread over a larger volume.

A comparison of the OH-PLIF standard deviation signal with the velocity fluctuations revealed the same trend. The high OH-PLIF standard deviation values were located in regions

5 with relatively low velocity fluctuations and vice versa, see Fig. 12. This is in contrast to that found under normal air confined combustion conditions, wherein the locations of OH-PLIF standard deviation and velocity fluctuations were observed to coincide relatively well, see Fig 10, specifically at the outer shear layer of the entry jet. In addition, the higher $\mathrm{OH}$ signal fluctuation for case 5 compared to case 4 contributed to the lower mean OH-PLIF signal 10 observed, compare Figs. 9 and 11.

To further confirm the impact of low oxygen concentration, OH-PLIF was performed for case 6, which has the same bulk velocity as case 5 but with oxygen concentration maintained at $21 \%$ rather than $14.5 \%$ in case 5 . This increase in air to maintain velocity resulted in lowering the equivalence ratio to 0.6. The results are shown in Fig. 13. The velocity vectors for this case are 15 also shown over the OH-PLIF signal.

OH-PLIF revealed that the flame under this condition maintained the same shape as that of case 4, where the flame formed a $\mathrm{V}$-shape albeit at a lower $\mathrm{OH}$ intensity signal. Also the flame starts to form inwards of the main velocity jet as opposed to outwards of the jet shown in Fig. 9. In addition, the main velocity jet had lower radial velocity compared to that of case 5.

20 These results outline that the difference between the reaction zone behavior for swirl flames and distributed combustion (cases 1 and 3 vs. case 2) is not caused by velocity increase due to dilution, but rather by the difference in the oxygen concentration and the reaction zone behavior rates. This is further confirmed by comparing cases 5 and 6 as they have the same bulk inlet 
velocity. The reaction rate under distributed combustion is significantly lower due to the reduced oxygen concentration in the reacting mixture.

This change in the reaction zone behavior also reflected on noise emission. As the combustor transitioned from swirl flame to distributed combustion, the combustion noise was significantly

5 reduced. The main frequency for this swirl flame was found to be $\sim 500 \mathrm{~Hz}$ and its harmonics [13]. The signal at this frequency disappeared upon transitioning to CDC with no other frequency detected. The overall noise signal was reduced from $80 \mathrm{~dB}$ to $63.5 \mathrm{~dB}$ under CDC condition [13]. This is directly attributed to small volumetric expansion of the gases with combustion under volume distributed combustion condition.

10 This transition, from swirl flame to distributed combustion, was not sudden. In the studies included herein, swirl flame (with $21 \% \mathrm{O}_{2}$ ) were compared to the low oxygen concentration case $\left(14.64 \% \mathrm{O}_{2}\right)$. Operating the combustor between those two extremities showed how the reaction zone shifted from one regime to the other, which is the focus of future studies. Figure 14 shows this transition using $\mathrm{OH}^{*}$ chemiluminescence.

15 This behavior in terms of reaction distribution is seen to be amongst the reason behind the significant gains of CDC. These gains include up to $85 \%$ reduction in terms of $\mathrm{NO}$ and $\mathrm{CO}$ emissions at different diluents temperatures [12], uniform thermal field (pattern factor) throughout the combustor [13], significantly reduced combustion noise emissions [13], and alleviation of flame fluctuation and combustion instability [12, 13]. These gains were 20 demonstrated under the same conditions examined here. In addition, these gains were demonstrated using methane, propane, and hydrogen enriched methane flames [25] which outlines fuel flexibility of the novel distributed combustion method. 


\section{Conclusions}

The velocity flowfield and reaction region under swirl flames and distributed combustion conditions have been investigated with focus on outlining the differences under these two conditions. Particle image velocimetry outlined the role of dilution on the isothermal flowfield of

5 the swirl burner flow, wherein it enhanced both the internal (central) and external recirculation zone. Velocity flowfield under reacting conditions revealed similar behavior for dilution; however, the maximum velocity shifted to downstream location as a result of combustion, along with the subsequent temperature increase and density decrease, which led to increased flow velocity.

10 A comparison of the reaction zone behavior to that of the velocity field showed significant differences between swirl flames and distributed combustion. In swirl flames, the reaction zone was located near the shear region between the entry jet and the inner/outer recirculation zone. This was supported by the close proximity of the the respective spatial locations of the mean velocity and OH-PLIF signal for both swirl cases investigated. The same was also observed for

15 the velocity fluctuations. Upon transitioning to distributed combustion, the opposite was observed. The reaction zone was located away from the high velocity region and the shear layer region. The reaction zone was established further downstream. In addition, the OH-PLIF signal fluctuation was found to be away from the velocity fluctuations around the entry jet. This stark difference between both cases explains the significant differences in pollutants emission and

20 uniform thermal field demonstrated under distributed combustion. Comparing distributed combustion with air dilution of swirl flame revealed that the forcing factor for distributed combustion is the lower oxygen concentration (achieved through entrainment of hot reactive 
gases, simulated here by $\mathrm{N}_{2} / \mathrm{CO}_{2}$ mixture) rather than increased bulk velocity and dilution through adding more air.

\section{Acknowledgments}

5 This research was supported by ONR and is gratefully acknowledged.

\section{References}

[1] Arghode VK, and Gupta AK. Effect of Flowfield for Colorless Distributed Combustion (CDC) for Gas Turbine Combustion. J. Applied Energy 2010;78:1631-40.

10 [2] Khalil AEE, and Gupta AK. Swirling Distributed Combustion For Clean Energy Conversion In Gas Turbine Applications. J. Applied Energy 2011;88:3685-93.

[3] Khalil AEE, Gupta AK, Bryden MK, Lee SC. Mixture Preparation Effects on Distributed Combustion for Gas Turbine Applications. J. Energy Resour. Technol. 2012;134(3):032201.

[4] Khalil AEE, and Gupta AK. Velocity and Turbulence Effect on Distributed Combustion 15 for Clean Gas Turbine Engines. J. Applied Energy 2014;125:1-9.

[5] Khalil AEE, and Gupta, AK. Fuel Flexible Distributed Combustion With Swirl For Gas Turbine Applications. J. Applied Energy, 2013;109:327-334.

[6] Tsuji H, Gupta AK, Hasegawa T, Katsuki M, Kishimoto K, Morita M. High temperature air combustion: from energy conservation to pollution reduction. Boca Raton: CRC Press.;2003

20 [7] Correa SM. A Review of NOx Formation under Gas-Turbine Combustion Conditions. Combustion Science and Technology 1992;87:329-62.

[8] Wunning JA, and Wunning JG. Flameless Oxidation to Reduce Thermal NO Formation. Progr. in Energy and Combustion Science 1997;23:81-94. 
[9] Lammel O, Schutz H, Schmitz G, Luckerath R, Stohr M, Noll B, Aigner M, Hase M, Krebs W. FLOX Combustion at High Power Density and High Flame Temperature. Journal of Engineering for Gas Turbine and Power 2010;132:121503.

[10] Weber R, Smart JP, Vd Kamp W. On the (MILD) Combustion of Gaseous, Liquid, and 5 Solid Fuels in High Temperature Preheated Air. Proceedings of the Combustion Institute 2005;30:2623-29.

[11] Khalil AEE, and Gupta, AK. Swirling Flowfield for Colorless Distributed Combustion. J. Applied Energy, 2014;113:208-218.

[12] Khalil AEE, and Gupta AK. Impact of Internal Entrainment on High Intensity Distributed

10 Combustion. J. Applied Energy, 2015;156:241-250.

[13] Khalil AEE, and Gupta AK. Thermal Field Investigation under Distributed Combustion Conditions. J. Applied Energy, 2015;160:477-488

[14] Weigand P, Meier W, Duan XR, Stricker W, and Aigner M. Investigations of Swirl Flames in a Gas Turbine Model Combustor. I. Flow Field, Structures, Temperature, and Species 15 Distributions. Combustion and Flame, 2006;144:205-224.

[15] Stohr M, Sadanandan R, and Meier W. Experimental Study of Unsteady Flame Structures of an Oscillating Swirl Flame in a Gas Turbine Model Combustor. Proc. Combust. Inst., 2009;32:2925-2932.

[16] Stopper U, Aigner M, Ax H, Meier W, Sadanandan R, Stohr M, and Bonaldo A. PIV, 20 2D-LIF and 1D-Raman Measurements of Flow Field, Composition and Temperature in Premixed Gas Turbine Flames. Exp. Thermal and Fluid Sci., 2010;34:396-403.

[17] Sadanandan R, Stohr M, and Meier W. Simultaneous OH-PLIF and PIV Measurements in a Gas Turbine Model Combustor. Appl. Phys B., 2008;90:609-618. 
[18] Han D, and Mungal MG. Simultaneous Measurement of Velocity and CH Layer Distribution in Turbulent Non-Premixed Flames. Proc. Combust. Inst., 2000;28:261-267.

[19] Kothnur S, Tsurikov MS, Clemens NT, Donbar JM, and Carter CD. Planar Imaging of $\mathrm{CH}, \mathrm{OH}$, and Velocity in Turbulent Non-Premixed Jet Flames. Proc. Combust. Inst., $5 \quad 2002 ; 29: 1921-1927$.

[20] Kim HS, Arghode VK, Linck MB, Gupta AK. Hydrogen Addition Effects in a Confined Swirl-Stabilized Methane-Air Flame. Int'l J. Hydrogen Energy, 2009;34(2):1054-1062.

[21] Thielicke W, and Stamhuis EJ. PIVlab - Time-Resolved Digital Particle Image Velocimetry Tool for MATLAB (version: 1.4). http://dx.doi.org/10.6084/m9.figshare.1092508

10 [22] Wang S, Mao J, Liu G. Uncertainty in the PIV Testing Results for Gas Flow Field Caused by Tracer Particles and Seeding Method. AIP Conference Proceedings, 2007;914:148155.

[23] Dieke $\mathrm{CH}$, and Crosswhite HM. The Ultraviolet Bands of OH. J. Quant. Spectrosc. Radiat. Transfer, 1962;2(2):97-199.

15 [24] Luque J, and Crosley DR. LIFBASE: Database and spectral simulation (version 1.5). SRI International Report MP 99-009, 1999.

[25] Khalil AEE, and Gupta AK. Fuel Property Effects on Distributed Combustion, Fuel, 2016;171:116-124

[26] Arndt C M, Steinberg A M, Boxx I G, Meier W, Carter C D, and Aigner M. Flow-Field 20 and Flame Dynamics of a Gas Turbine Model Combustor During Transition Between ThermoAcoustically Stable und Unstable States. Proc. ASME Turbo Expo, 2010, GT2010-22830 
[27] Oberleithner K, Stöhr M, Im S H, Arndt C M, and Steinberg A M. Formation and FlameInduced Suppression of the Precessing Vortex Core in a Swirl Combustor: Experiments and Linear Stability Analysis. Combustion and Flame, 2015;162:3100-3114

[28] Stone R, Clarke A, and Beckwith P. Correlations for the Laminar-Burning Velocity of 5 Methane/Diluent/Air Mixtures Obtained in Free-Fall Experiments. Combustion and Flame, 1998;114:546-555.

[29] Han P, Checkel MD, Fleck BA, Nowicki NL. Burning Velocity of Methane/Diluent Mixture with Reformer Gas Addition. Fuel, 2007;86:585-596.

[30] Galmiche B, Halter F, Foucher F, Dagaut P. Effects of Dilution on Laminar Burning 10 Velocity of Premixed Methane/Air Flames. Energy \& Fuels, 2011;25:948-954.

[31] Nicol DG, Malte PC, Hamer AJ, Roby RJ, Steele RC. Development of a Five-Step Global Methane Oxidation-NO Formation Mechanism for Lean-Premixed Gas Turbine Combustion. J. Eng. Gas Turbines Power, 1999;121(2):272-280 
Figure Captions

Figure 1. $\mathrm{OH}^{*}$ Chemiluminescence intensity distribution for four flame conditions

Figure 2. Schematic of the swirl configuration

Figure 3. Schematic of the experiments including flow controls and laser diagnostics

Figure 4. Flame images for different oxygen concentration (with change in diluents amount)

Figure 5. Axial mean velocity vectors (left) and axial velocity fluctuations (right) for case 1

Figure 6. Axial mean velocity vectors (left) and axial velocity fluctuations (right) for case 2

Figure 7. Axial mean velocity vectors (left) and axial velocity fluctuations (right) for case 4

10 Figure 8. Axial mean velocity vectors (left) and axial velocity fluctuations (right) for case 5

Figure 9. OH-PLIF mean signal and velocity vectors overlaid for case 4

Figure 10. OH-PLIF fluctuations (left) and axial velocity fluctuations (right) for case 4

Figure 11. OH-PLIF mean signal and velocity vectors overlaid for case 5

Figure 12. OH-PLIF fluctuations (left) and axial velocity fluctuations (right) for case 5

15 Figure 13. OH-PLIF mean signal with velocity vectors overlaid for case 6

Figure 14. Change in $\mathrm{OH}^{*}$ chemiluminescence with decrease in oxygen concentration 
Table Captions

Table 1. PIV Parameters

Table 2. Experimental parameters 


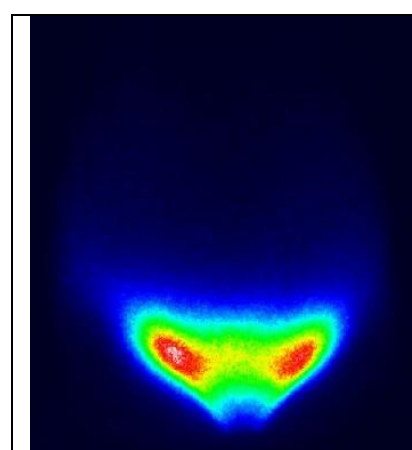

Phi $=0.9, \mathrm{O}_{2}=21 \%$

Re 4450

NO=13.3 PPM

0

16000

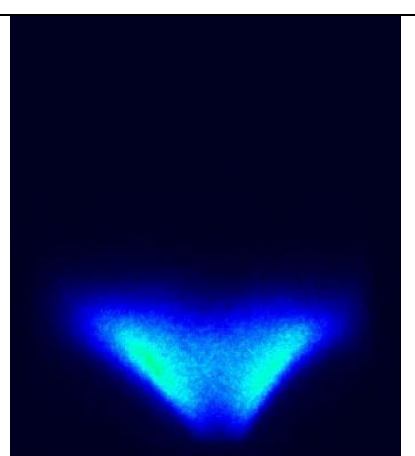

Phi $=0.6, \mathrm{O}_{2}=21 \%$

Re 6450

NO=2.26 PPM

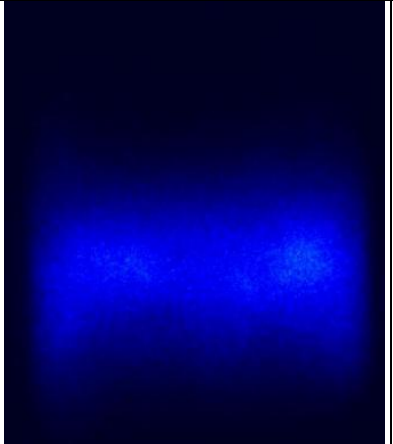

Phi $=0.9, \mathrm{O}_{2}=13.8 \%$

Re 6800

NO $=1.8$ PPM

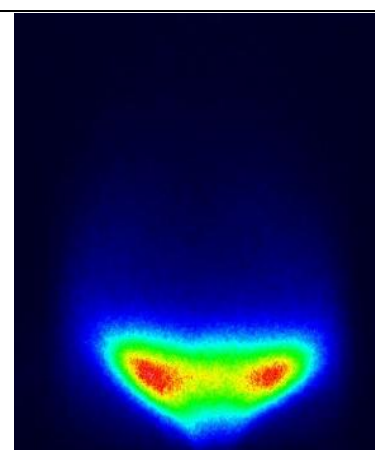

Phi $=0.9, \mathrm{O}_{2}=21 \%$

$\operatorname{Re} \sim 6650$

NO=13.3 PPM

Figure 1. OH* Chemiluminescence intensity distribution for four flame conditions 


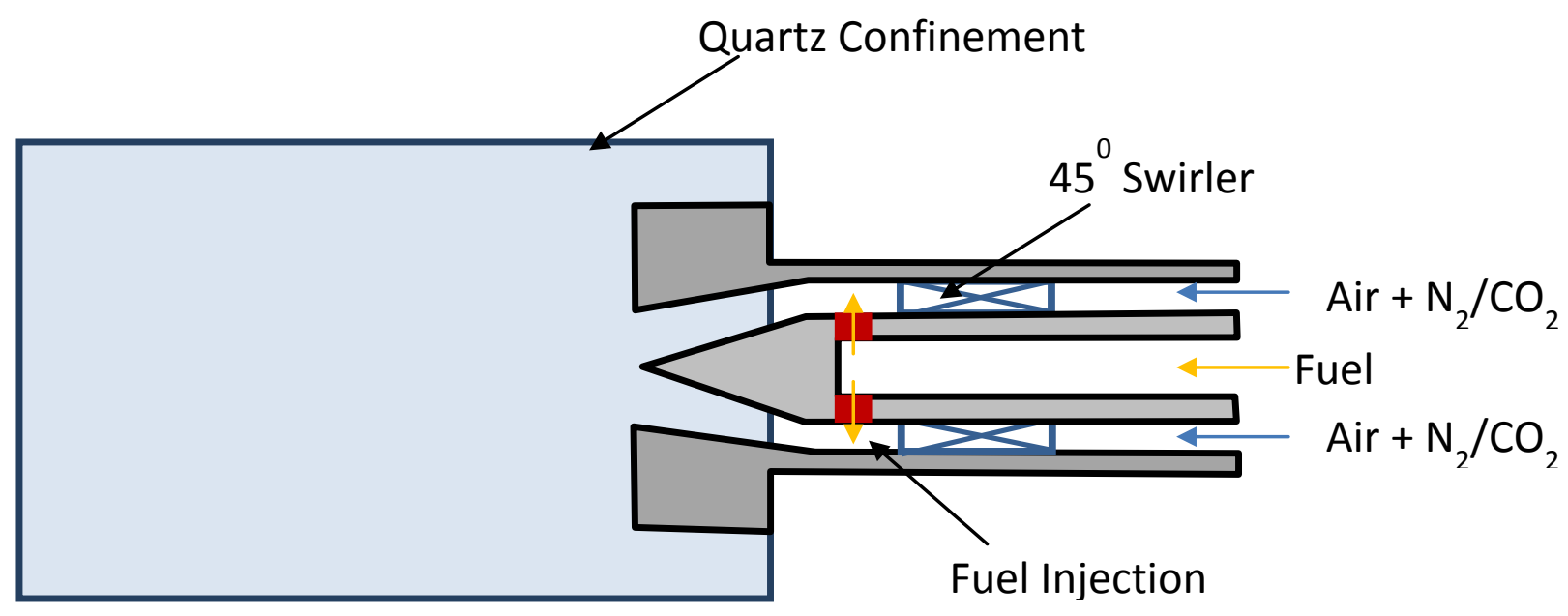

Figure 2. Schematic of the swirl configuration 


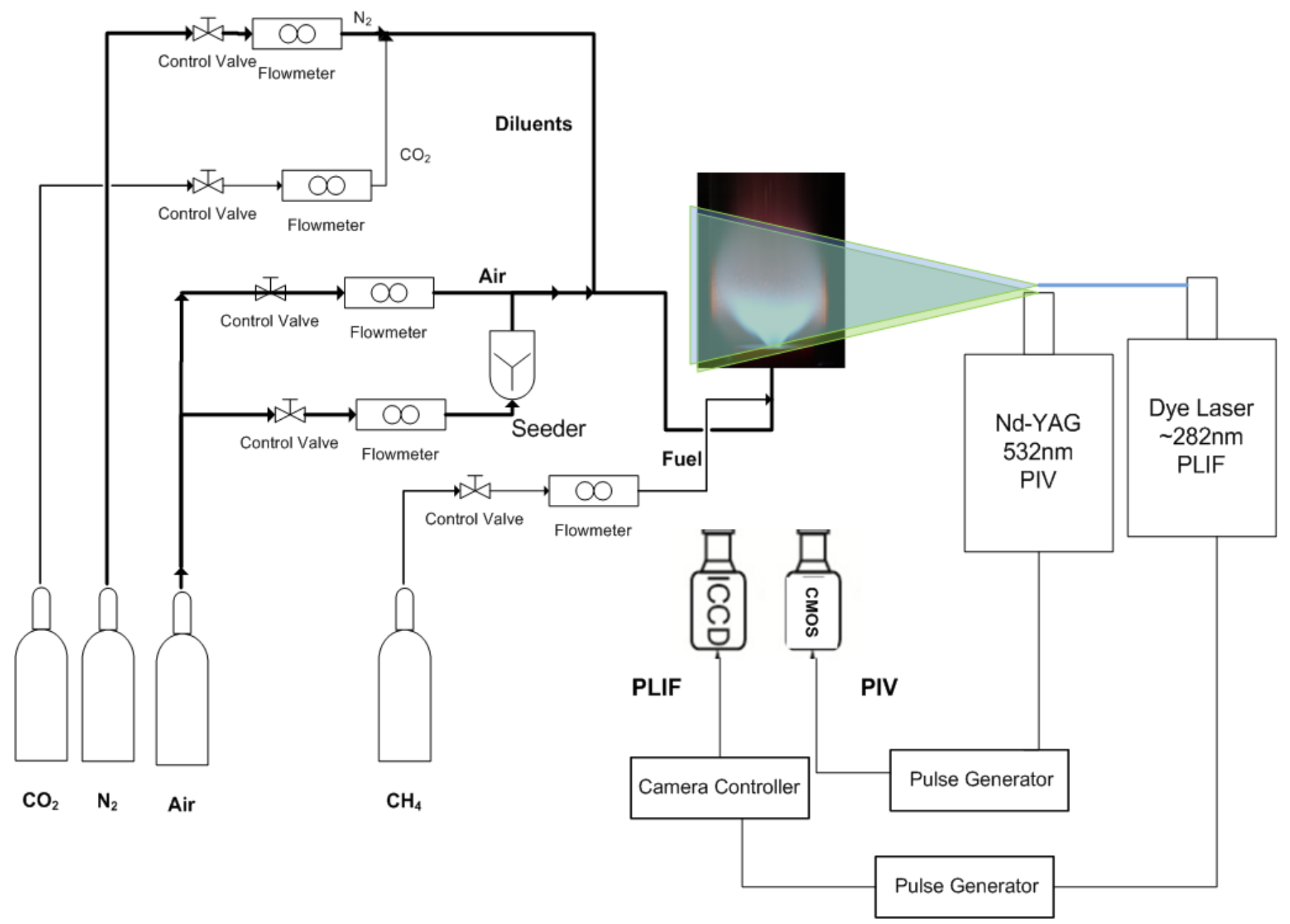

Figure 3. Schematic of the experiments including flow controls and laser diagnostics 


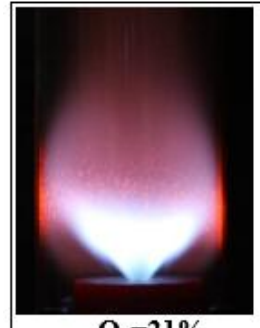

$\mathrm{O}_{2}=21 \%$
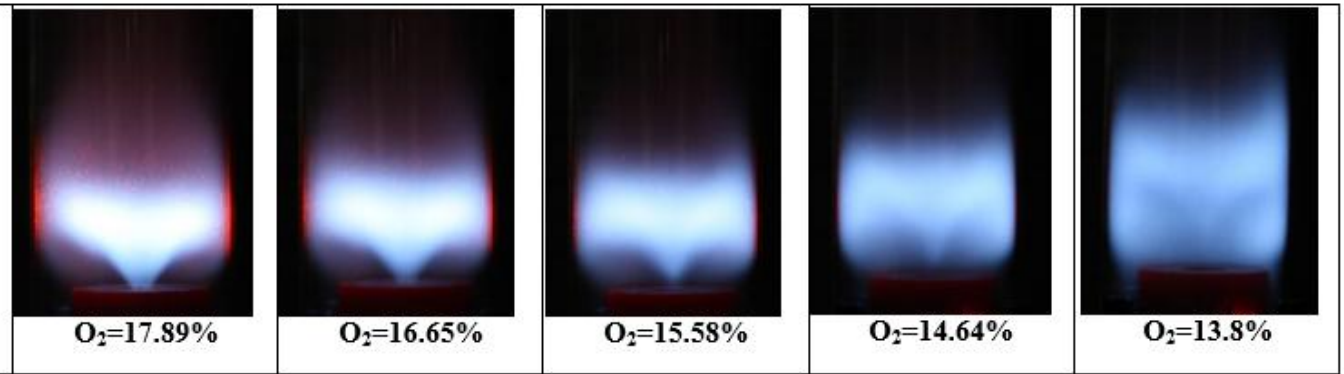

Figure 4. Flame images for different oxygen concentration (with change in diluents amount) 


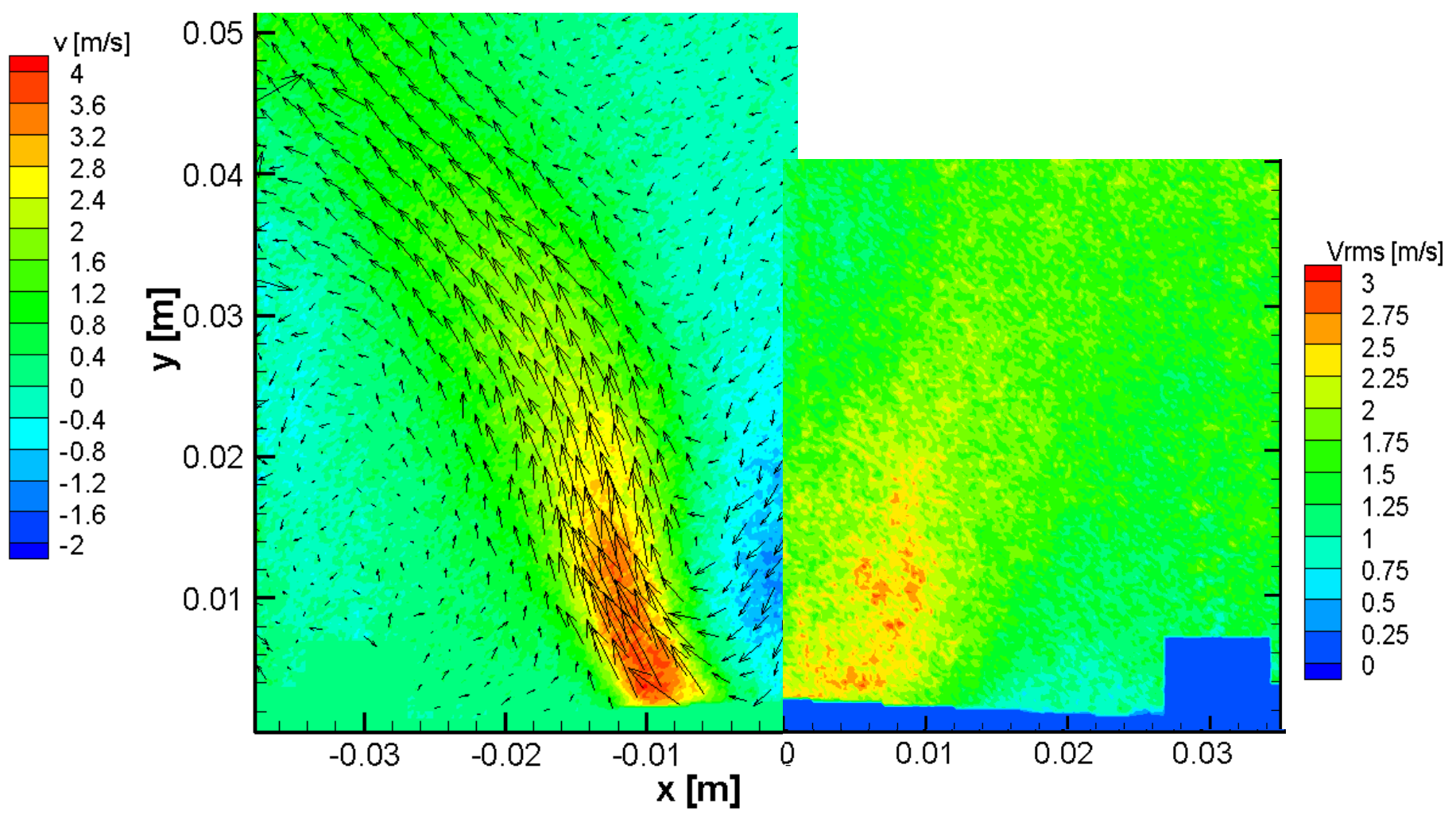

Figure 5. Axial mean velocity vectors (left) and axial velocity fluctuations (right) for case 1 


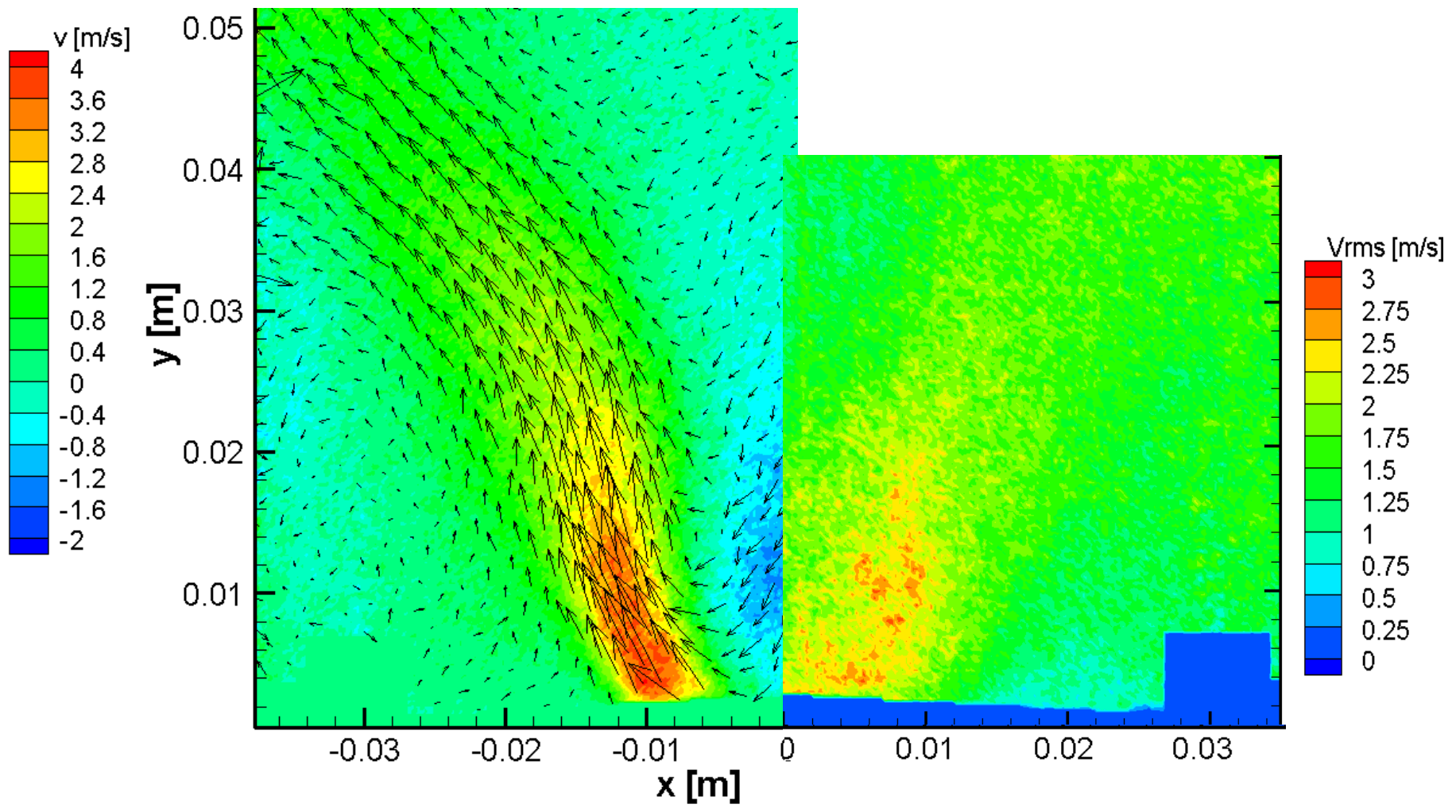

Figure 5. Axial mean velocity vectors (left) and axial velocity fluctuations (right) for case 


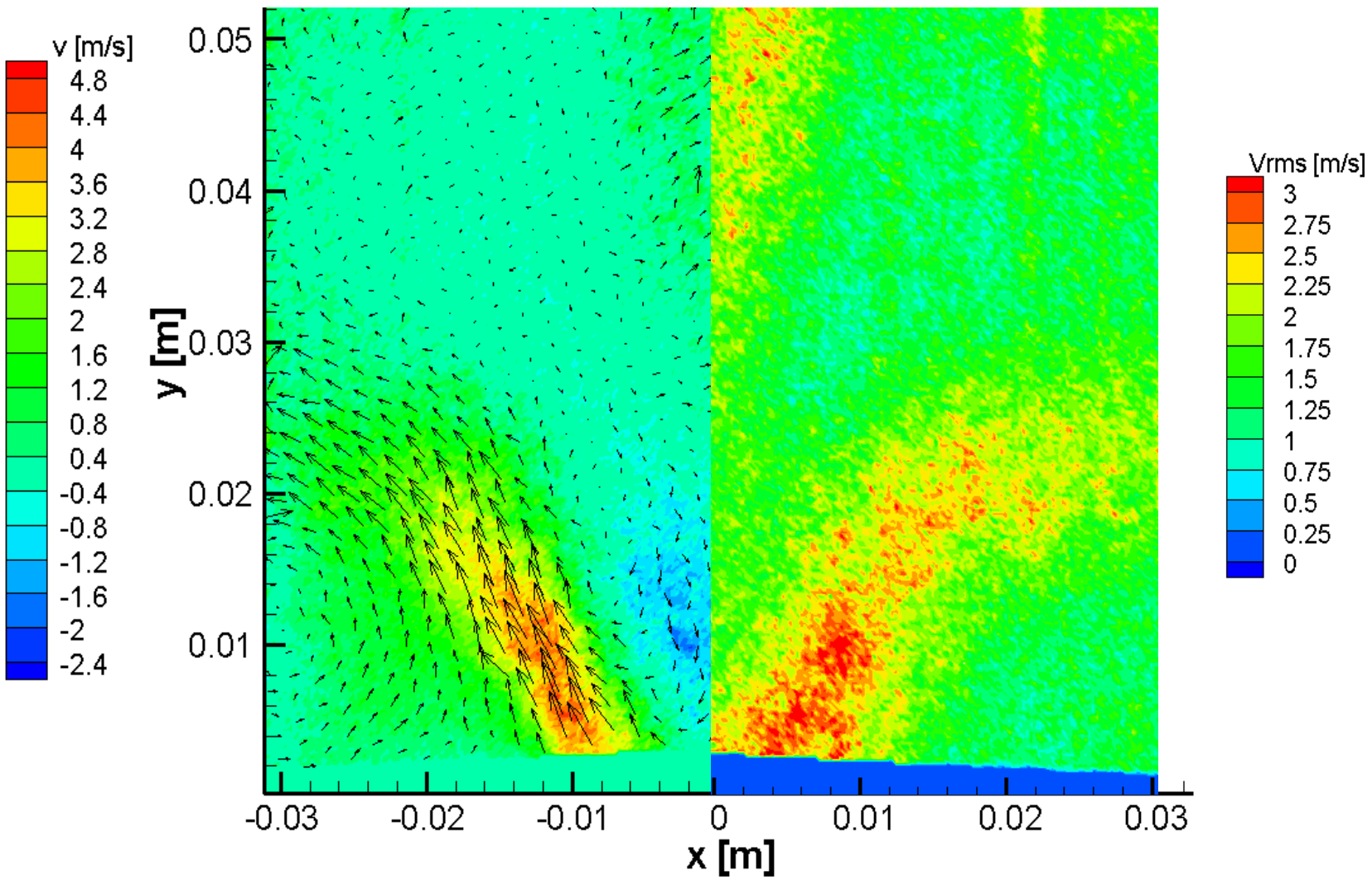

Figure 6. Axial mean velocity vectors (left) and axial velocity fluctuations (right) for case 2 


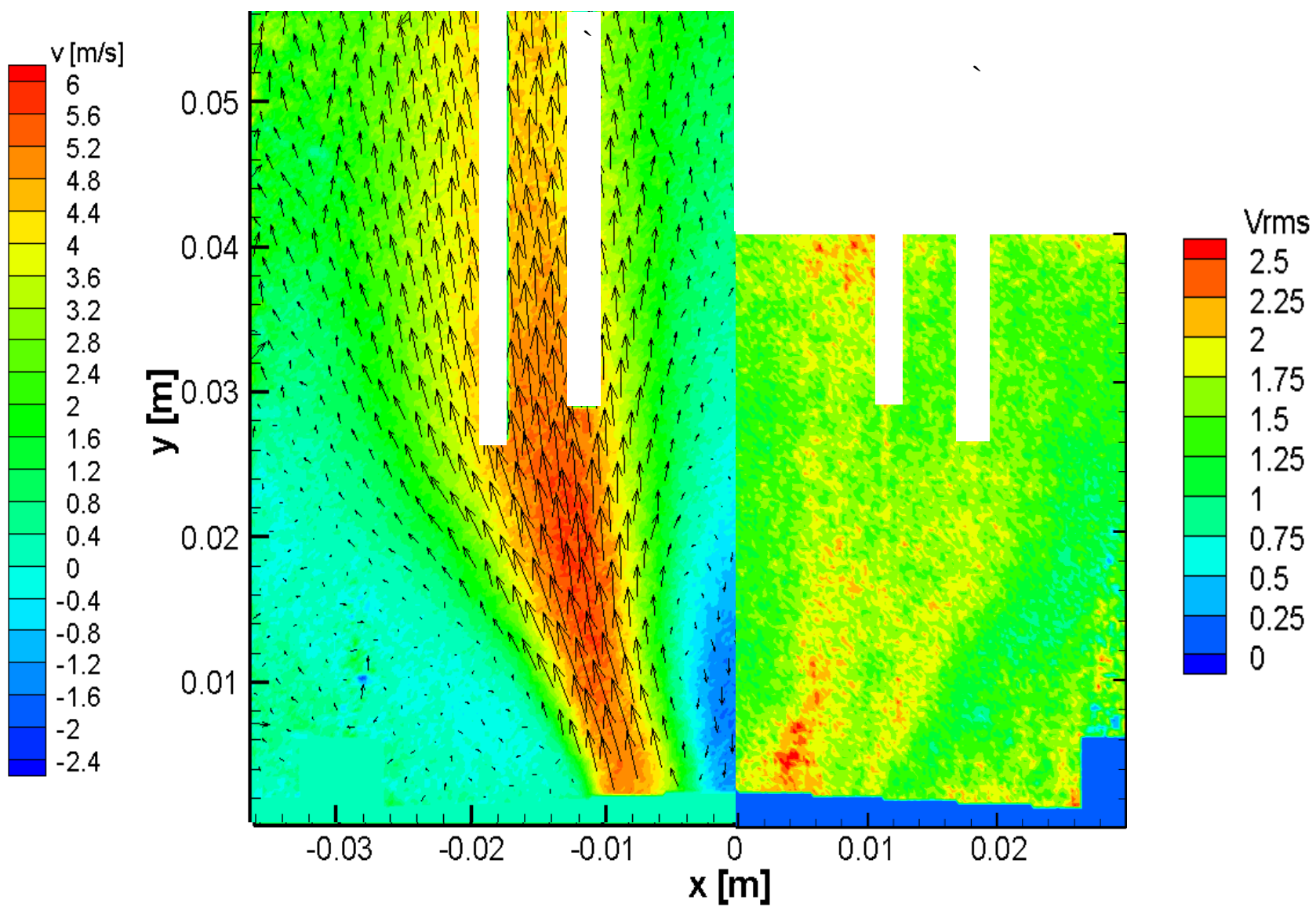

Figure 7. Axial mean velocity vectors (left) and axial velocity fluctuations (right) for case 4 


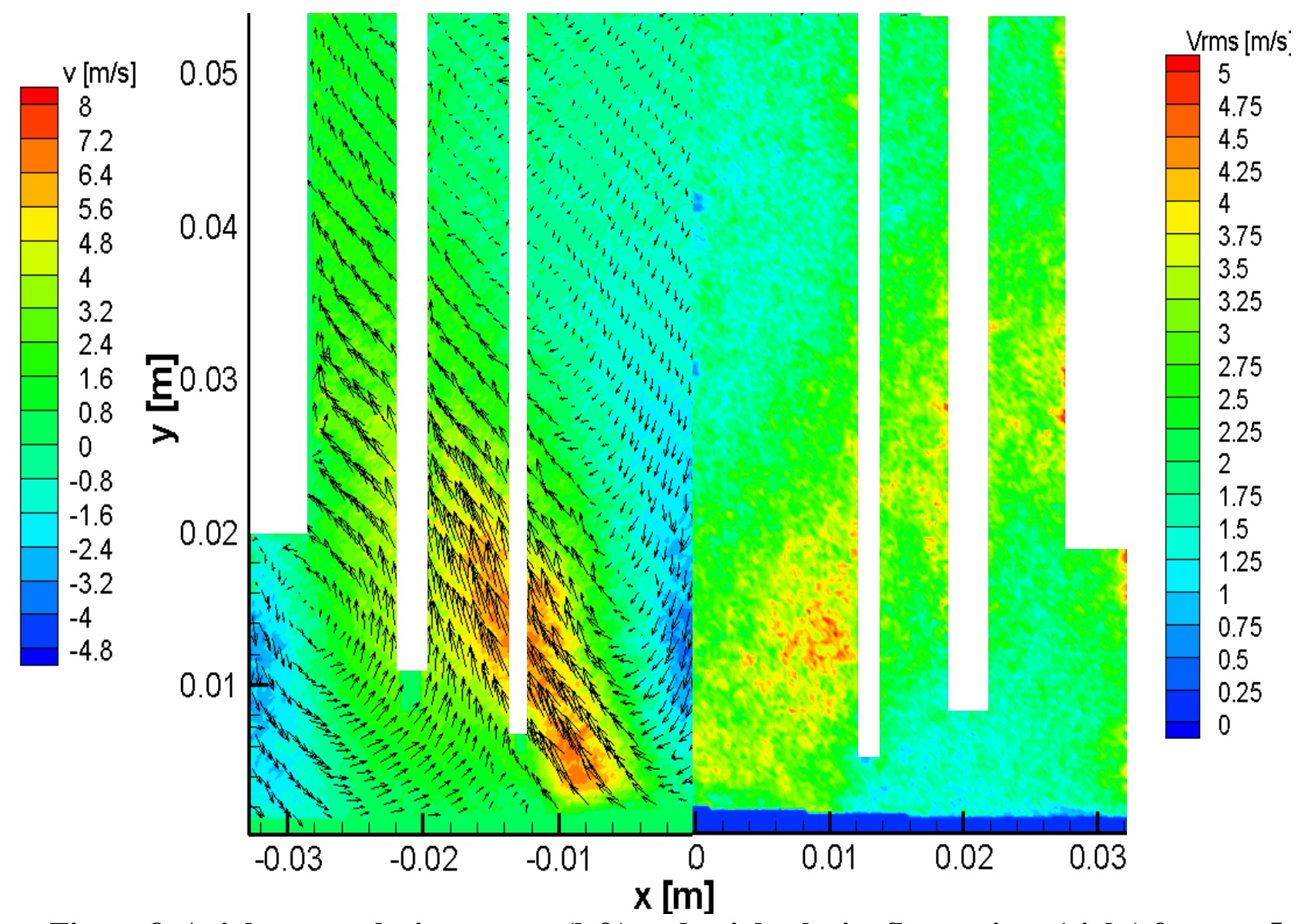

Figure 8. Axial mean velocity vectors (left) and axial velocity fluctuations (right) for case 5 


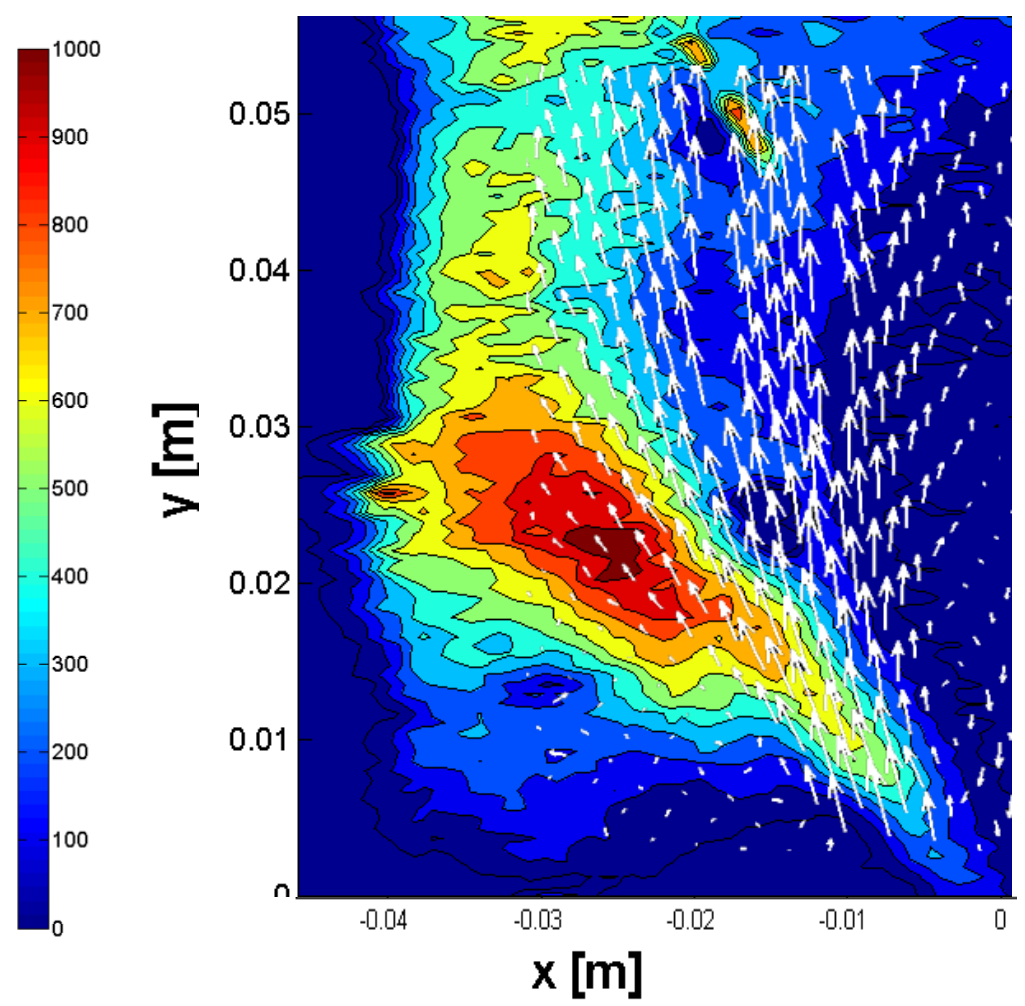

Figure 9. OH-PLIF mean signal and velocity vectors overlaid for case 4 


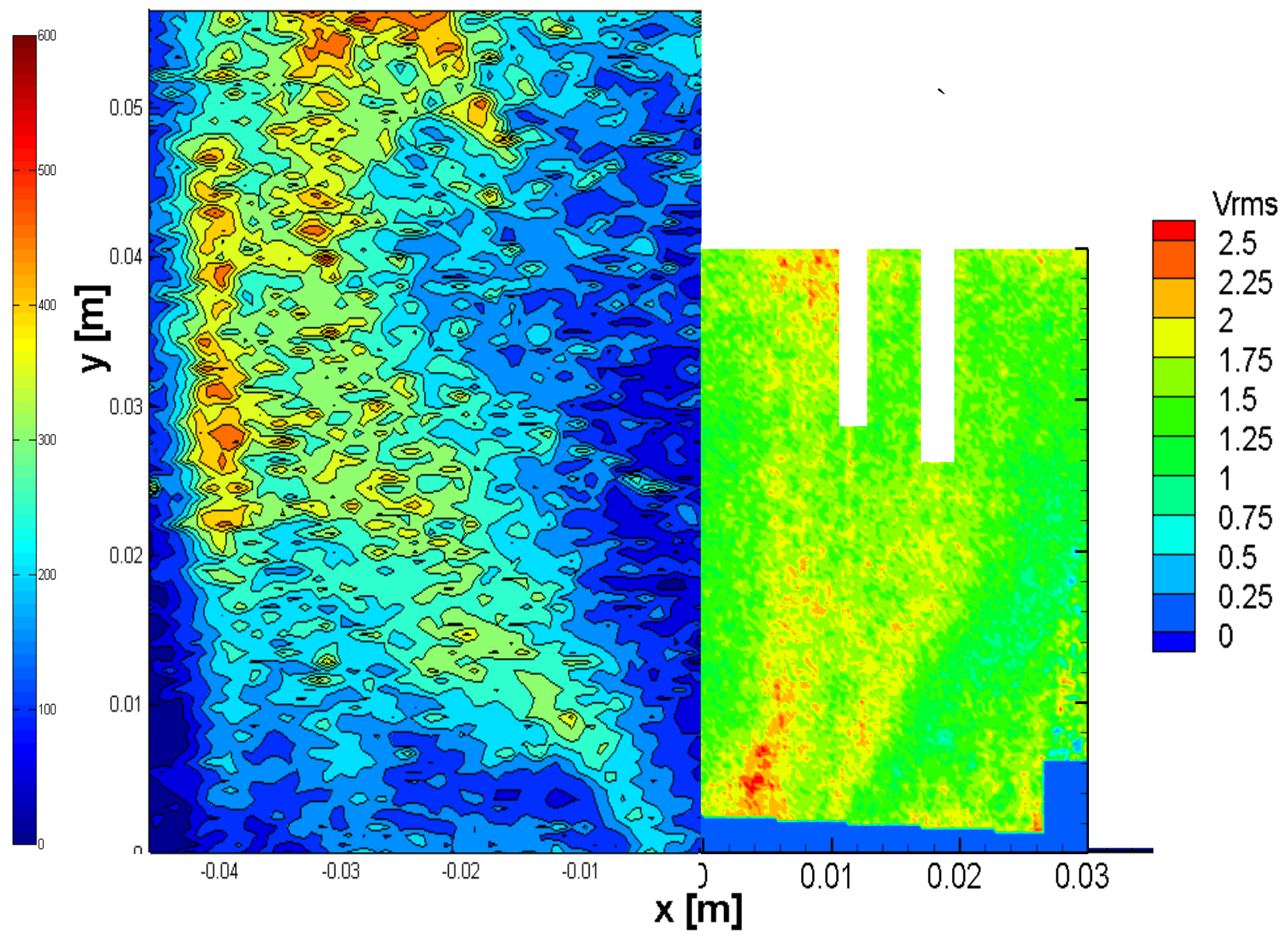

Figure 10. OH-PLIF fluctuations (left) and axial velocity fluctuations (right) for case 4 


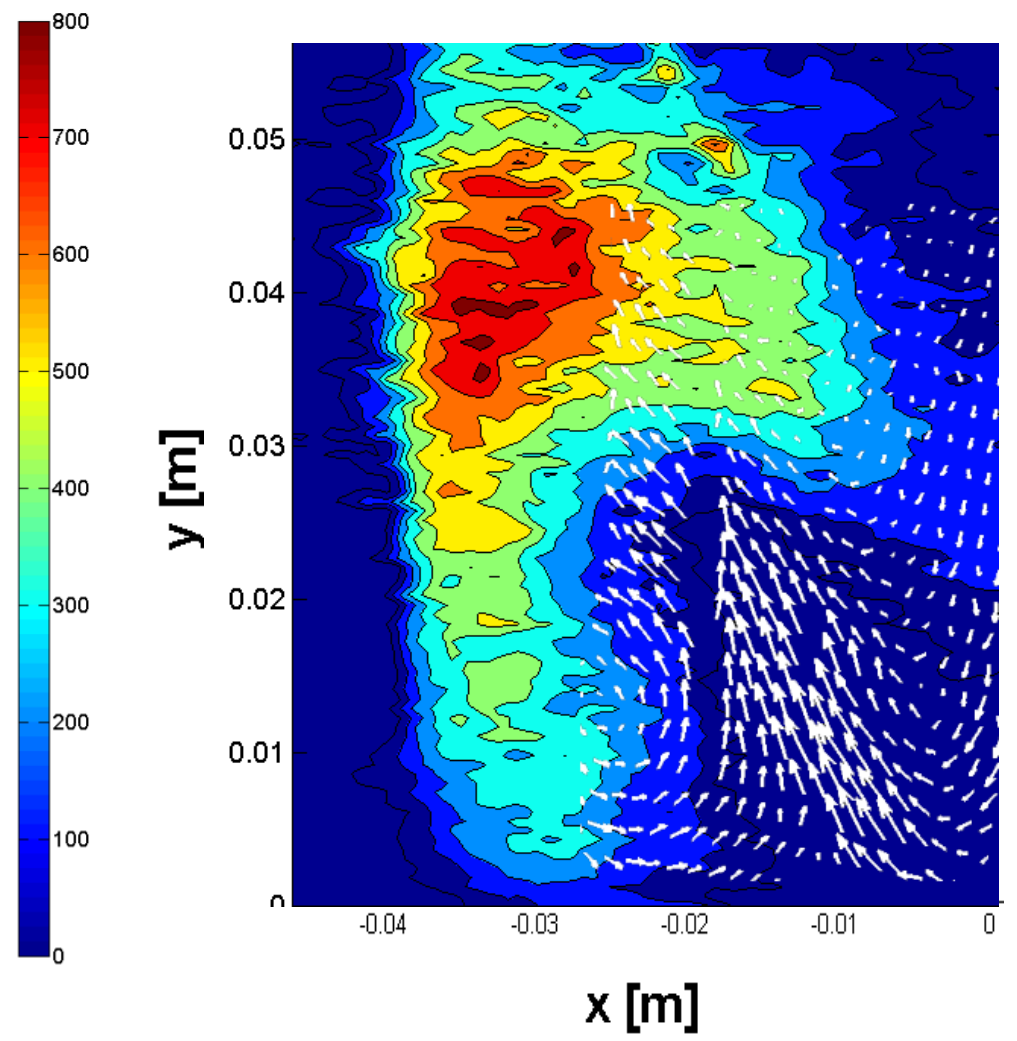

Figure 11. OH-PLIF mean signal and velocity vectors overlaid for case 5 


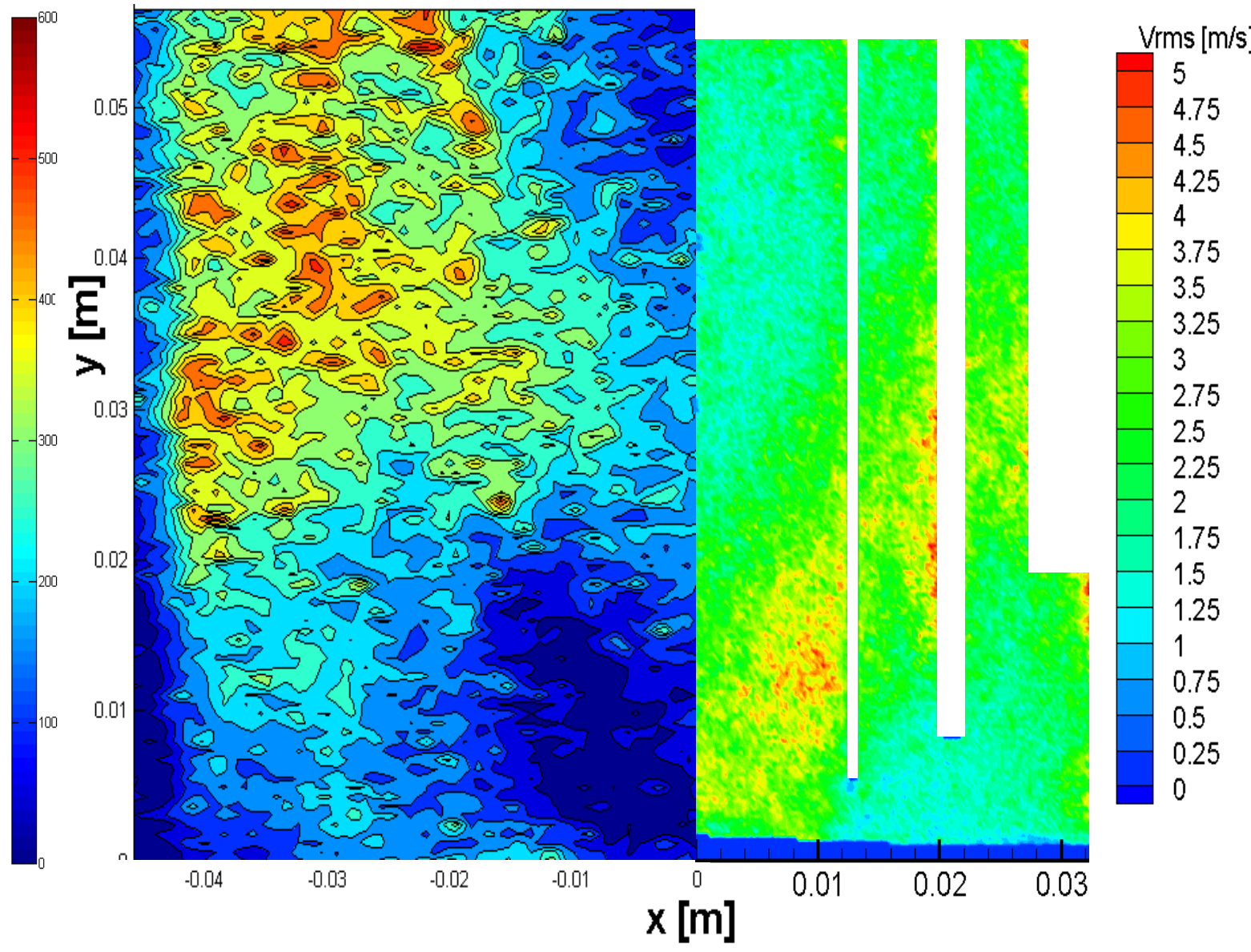

Figure 12. OH-PLIF fluctuations (left) and axial velocity fluctuations (right) for case 5 


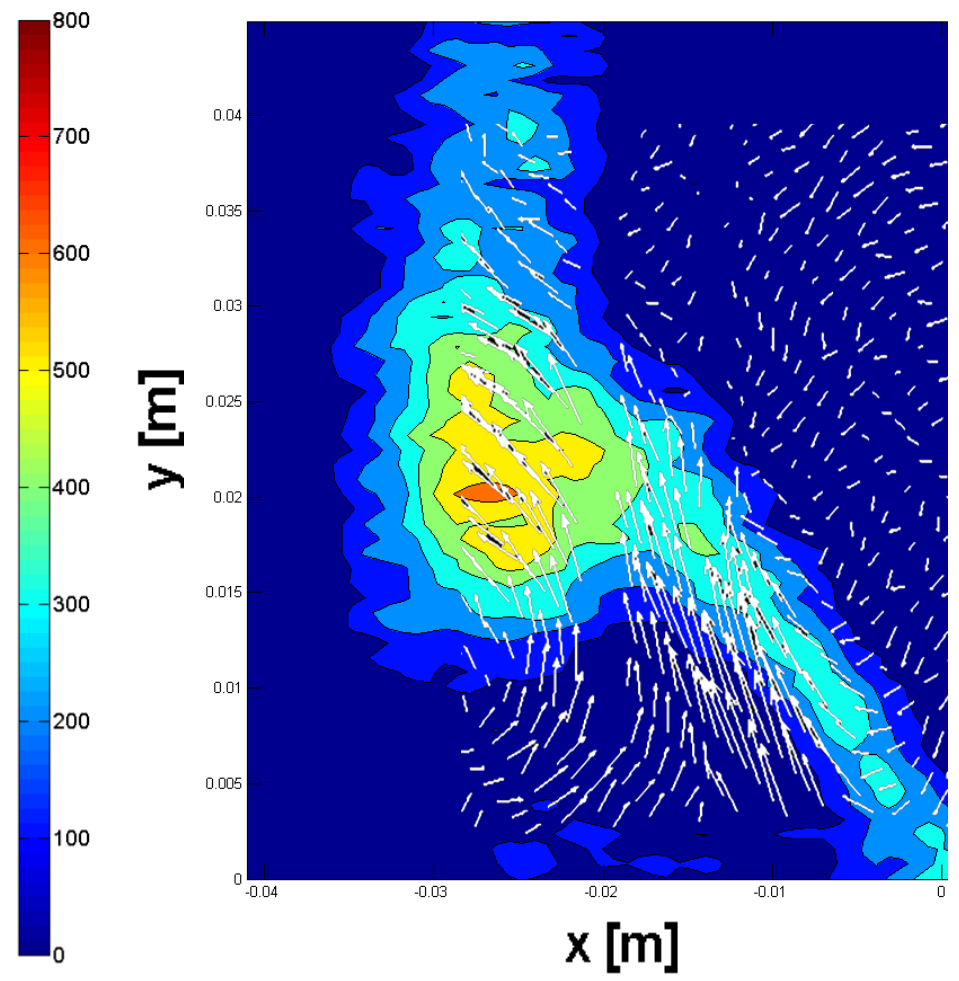

Figure 13. OH-PLIF mean signal with velocity vectors overlaid for case 6 


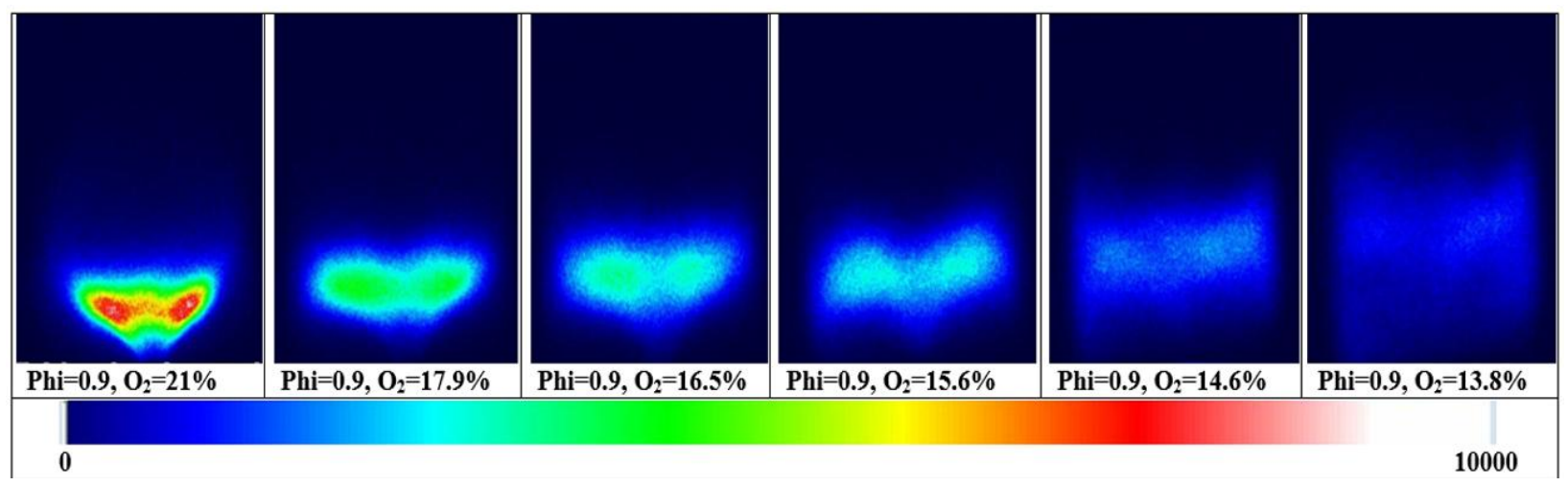

Figure 14. Change in $\mathrm{OH}^{*}$ chemiluminescence with decrease in oxygen concentration 
Table 1. PIV Parameters

\begin{tabular}{|c|c|}
\hline Seeding Particle & Alumina \\
\hline Size & $2 \mu \mathrm{m}$ \\
\hline Rate & $5 \mathrm{~Hz}$ \\
\hline No. of Image Pairs & $\mathbf{1 0 0}$ \\
\hline Laser Sheet Thickness & $\sim \mathbf{m m}$ \\
\hline Pulse Separation & $\mathbf{6 0} \boldsymbol{\mu s}$ \\
\hline Interrogation Window Size & Multiple, 64x64 to 8x8, 50\% overlap \\
\hline Camera Resolution & $\mathbf{1 3 6 0} \times 1036$ pixels \\
\hline Velocity Field Spatial Resolution & $\mathbf{0 . 5} \mathbf{0 . 5} \mathbf{~ m m}$ \\
\hline Lens Focal Length & $\mathbf{6 0 m m}$ \\
\hline f-stop Setting & 2.8 \\
\hline Seeding Air Percentage & $\sim 10 \%$ \\
\hline
\end{tabular}


Table 2. Experimental parameters

\begin{tabular}{|c|c|c|c|c|c|c|c|}
\hline & \multicolumn{4}{|c|}{ Flow Rates [L/min] } & \multirow{2}{\text{Oxygen}}{$\begin{array}{c}\text { Equivalence } \\
\text { Ratio }\end{array}$} & $\begin{array}{c}\text { Reynolds' } \\
\text { Number }\end{array}$ \\
\cline { 2 - 5 } & Air & Fuel & $\mathrm{N}_{2}$ & $\mathrm{CO}_{2}$ & Concentration [\%] & - & 4080 \\
\hline 1 & $63.9 \pm 0.9$ & - & - & - & $21 \%$ & - & 6050 \\
\hline 2 & $63.9 \pm 0.9$ & - & $25 \pm 0.38$ & $2.78 \pm 0.04$ & $14.5 \%$ & - & 6080 \\
\hline 3 & $95 \pm 1.4$ & - & - & - & $21 \%$ & 0.9 & 4450 \\
\hline 4 & $63.9 \pm 0.9$ & $6 \pm 0.1$ & - & - & $21 \%$ & 0.9 & 6430 \\
\hline 5 & $63.9 \pm 0.9$ & $6 \pm 0.1$ & $25 \pm 0.38$ & $2.78 \pm 0.04$ & $14.5 \%$ & 0.6 & 6450 \\
\hline 6 & $95 \pm 1.4$ & $6 \pm 0.1$ & - & - & $21 \%$ & & \\
\hline
\end{tabular}

